\title{
Diclofenac Administration after Physical Training Blunts Adaptations of Peripheral Systems and Leads to Losses in Exercise Performance: In Vivo and In Silico Analyses
}

\author{
Rômulo Pillon Barcelos ${ }^{1,2, *}$, Frederico Diniz Lima ${ }^{3}$, Aline Alves Courtes ${ }^{1}$, Ingrid Kich da Silva ${ }^{1}$, \\ Jose Eduardo Vargas ${ }^{4,5}$, Luiz Fernando Freire Royes ${ }^{3}{ }^{(}$, Cristiano Trindade ${ }^{6, *} \mathbb{C}^{\circ}$, Javier González-Gallego ${ }^{7}$ (i) \\ and Félix Alexandre Antunes Soares ${ }^{1}$
}

check for

updates

Citation: Barcelos, R.P.; Lima, F.D.; Courtes, A.A.; Silva, I.K.d.; Vargas, J.E.; Royes, L.F.F.; Trindade, C.; González-Gallego, J.; Soares, F.A.A. Diclofenac Administration after Physical Training Blunts Adaptations of Peripheral Systems and Leads to Losses in Exercise Performance: In Vivo and In Silico Analyses. Antioxidants 2021, 10, 1246. https://doi.org/10.3390/ antiox10081246

Academic Editor:

Athanasios Jamurtas

Received: 30 June 2021

Accepted: 29 July 2021

Published: 4 August 2021

Publisher's Note: MDPI stays neutral with regard to jurisdictional claims in published maps and institutional affiliations.

Copyright: (c) 2021 by the authors. Licensee MDPI, Basel, Switzerland. This article is an open access article distributed under the terms and conditions of the Creative Commons Attribution (CC BY) license (https:/ / creativecommons.org/licenses/by/ $4.0 /)$.
1 Programa de Pós-Graduação em Bioquímica Toxicológica, Centro de Ciências Naturais e Exatas, Departamento de Bioquímica e Biologia Molecular, Universidade Federal de Santa Maria, Santa Maria 97105-900, Brazil; alinecourtes@bol.com.br (A.A.C.); ingrid.ksilva@gmail.com (I.K.d.S.); felix@ufsm.br (F.A.A.S.)

2 Programa de Pós-Graduação em Bioexperimentação (PPGBioexp), Universidade de Passo Fundo (UPF), BR 285, Passo Fundo 99052-900, Brazil

3 Laboratório de Bioquímica do Exercício, Centro de Educação Física e Desportos, Universidade Federal de Santa Maria, Santa Maria 97105-900, Brazil; profred@gmail.com (F.D.L.); nandoroyes@yahoo.com.br (L.F.F.R.)

4 Laborátorio de Biologia Molecular, Instituto de Ciências Biológicas (ICB), Universidade de Passo Fundo (UPF), Passo Fundo 99052-900, Brazil; josevargas@upf.br

5 Hospital de Clínicas de Porto Alegre, Programa de Pós-Graduação Ciências em Gastroenterologia e Hepatologia, Universidade Federal do Rio Grande do Sul (UFRGS), Porto Alegre 90035-003, Brazil

6 Facultad de Ciencias Básicas y Biomédicas, Universidad Simón Bolívar, Barranquilla 080002, Colombia

7 Institute of Biomedicine (IBIOMED) and Centro de Investigación Biomédica en Red de Enfermedades Hepáticas y Digestivas (CIBERehd), University of León, 24071 León, Spain; jgonga@unileon.es

* Correspondence: romulopillon@upf.br (R.P.B.); cristiano.trindade@unisimonbolivar.edu.co (C.T.)

Abstract: Recovery in athletes is hampered by soreness and fatigue. Consequently, nonsteroidal antiinflammatory drugs are used as an effective strategy to maintain high performance. However, impact of these drugs on adaptations induced by training remains unknown. This study assessed the effects of diclofenac administration $(10 \mathrm{mg} / \mathrm{kg} /$ day) on rats subjected to an exhaustive test, after six weeks of swimming training. Over the course of 10 days, three repeated swimming bouts were performed, and diclofenac or saline were administered once a day. Trained animals exhibited higher muscle citrate synthase and lower plasma creatinine kinase activities as compared to sedentary animals, wherein diclofenac had no impact. Training increased time to exhaustion, however, diclofenac blunted this effect. It also impaired the increase in plasma and liver interleukin-6 levels. The trained group exhibited augmented catalase, glutathione peroxidase, and glutathione reductase activities, and a higher ratio of reduced-to-oxidized glutathione in the liver. However, diclofenac treatment blunted all these effects. Systems biology analysis revealed a close relationship between diclofenac and liver catalase. These results confirmed that regular exercise induces inflammation and oxidative stress, which are crucial for tissue adaptations. Altogether, diclofenac treatment might be helpful in preventing pain and inflammation, but its use severely affects performance and tissue adaptation.

Keywords: NSAIDs; physical training; rat; diclofenac; inflammation; oxidative stress; systems biology; systems pharmacology; adaptation

\section{Introduction}

A regular exercise regime is well-known to confer significant health benefits. In particular, it reduces the risk of severe diseases, including type 2 diabetes, cardiovascular diseases, cancer, or neurodegeneration. In general, regular exercising plays a pivotal role in maintaining and improving organism functions, and also influences growth and life expectancy $[1,2]$. However, acute exercise may lead to inflammation and a redox imbalance 
in the body, which further induces the activation of various signaling pathways in tissues, such as muscle and the liver. Despite their possible role in incurring damaging effects, inflammation and oxidative stress are also known to be involved in the exercise-induced adaptation process [3]. Thus, acute and exhausting exercises induce an increase in the levels of various circulating cytokines and chemokines, including interleukin-1 (IL-1), IL-6, and tumor necrosis factor- $\alpha$ (TNF- $\alpha$ ), which could either harm the organism or may assist in tissue adaptation after a period of recovery [4]. However, during sports competitions, athletes are required to perform the tasks within small intervals, sometimes days or maybe a few hours, and thus they do not get ample time to ensure sufficient recovery. As a consequence, nonsteroidal anti-inflammatory drugs (NSAIDs) are commonly used to decrease the acute inflammatory response, soreness, and pain during such competitions. During the last decade, diclofenac was one of the most commonly prescribed over-thecounter NSAIDs [5].

Similar to classic NSAIDs, diclofenac also acts via inhibition of cyclooxygenase enzyme activities that decreases the production of prostaglandin endoperoxides, and thus relieves inflammation and pain. In particular, diclofenac is prescribed during sports competitions to reduce pain-related symptoms, while ensuring fast recovery from previous strenuous exercises and enabling constant preparation for the next competitive task [6,7]. Recent studies from our laboratory demonstrated that diclofenac pretreatment decreased the expression and protein content of several molecules involved in inflammatory pathways, including TNF- $\alpha$, toll-like receptor-4, or p65 nuclear factor kappa B (NF- $\kappa \mathrm{B}$ ) subunit, after eccentric exercise bouts in rat muscle [8] and liver [9]. Such pretreatment might assist in fast recovery; however, this may also lead to non-adapted tissues, thereby limiting some of the beneficial effects of training.

Regular physical training involves a different set of adaptation mechanisms as compared to acute exercise $[10,11]$. However, no information is currently available regarding the association between NSAIDs and the effects of training on plasma or peripheral organs, such as the liver. In recent years, systems pharmacology has emerged as a holistic approach in pharmacology that provides novel insights to unravel molecular mechanisms involved in the action of drugs [12-14]. In particular, the use of in silico analysis, based on this approach, might aid in the identification of molecular targets of diclofenac that mediate the physiological adaptation to exercise. Thus, this study aimed to investigate the overall impact of diclofenac on the response to acute bouts of exercise after a 6-week training period. The study combined the results of molecular analysis, obtained from an in vivo study, with systems pharmacology predictions, and identified changes in the redox and inflammatory status.

\section{Materials and Methods}

\subsection{Animals and Ethics Statement}

The present study utilized 3-month-old male Wistar rats, weighing $270 \pm 25 \mathrm{~g}$, obtained from our own breeding colony (UFSM), for in vivo experiments. The animals were maintained in an air-conditioned room at $25 \pm 1{ }^{\circ} \mathrm{C}$ with $55 \%$ relative humidity and $12 / 12 \mathrm{~h}$ light/dark cycle. The animals were fed standard laboratory chow and had free access to water. All experimental procedures were conducted in accordance with the National and International Legislations, Brazilian College of Animal Experimentation (COBEA) and the US Public Health Service's Policy on Human Care and Use of Laboratory Animals-PHS Policy. The experimental protocols included in the study were approved by the local Ethics Committee.

\subsection{Experimental Design and Diclofenac Administration}

One week prior to swimming training, the animals were initially exposed to water conditions for acclimatization, with the aim to reduce stress and make them acquainted to the exercise environment. In particular, the water adaptation process involved keeping the animals in shallow water ( $5 \mathrm{~cm}$ in depth) at $31 \pm 1^{\circ} \mathrm{C}$ from 9 am to $11 \mathrm{am}$, for one 
week. Following this, the animals were randomly divided into two groups, training $(n=21)$ and sedentary $(n=21)$ groups. The training group was subjected to a 6 -week swimming training program with bodyweight overload of $5 \%$ of body weight, 60 min per day for 6 weeks $[15,16]$. The tank used for training was $80 \mathrm{~cm}$ in length, $50 \mathrm{~cm}$ in width, and $90 \mathrm{~cm}$ deep. The swimming training was always performed with water temperature at $31 \pm 1{ }^{\circ} \mathrm{C}$,

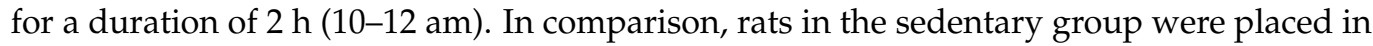
a separate but similar tank, with shallow water $(5 \mathrm{~cm})$, at the same temperature for $30 \mathrm{~min}$, 5 days a week, and without any back overload. At the end of each training schedule, rats were towel-dried and returned to their respective cages.

After completion of the training process, both training and sedentary groups were subdivided into saline or diclofenac administration groups. Thus, the study involved a total of four groups, namely group I, Sed-Sal, sedentary untrained animals, treated with saline (vehicle; $n=10$ ); group II, Sed-Diclo, sedentary untrained animals, treated with diclofenac $10 \mathrm{mg} / \mathrm{kg} /$ day $(n=10)$; group III, Exe-Sal, 6-week swimming trained animals, treated with saline (vehicle) $(n=11)$; and group IV, Exe-Diclo, 6-week swimming trained animals, treated with diclofenac $10 \mathrm{mg} / \mathrm{kg} /$ day $(n=11)$. Following a previously established method to simulate the use of diclofenac during competition tasks, the swimming groups were subjected to three exhaustive swimming bouts, where each bout was separated by a period of $72 \mathrm{~h}$ [9].

Diclofenac (Sigma-Aldrich, St. Louis, MO, USA) was administered orally by intragastric gavage, at a dose of $10 \mathrm{mg} / \mathrm{kg}$ body weight (in saline) for 9 days. This dose was used in previous studies [9,17] and is and is below those known to induce hepatotoxicity [18,19]. Prior to the first exhaustion bout, the animals were pretreated for three days, and the treatment was continued till the last day of the protocol. The non-treated animals received saline during the same treatment period.

Following the last bout, rats were sacrificed by decapitation. After exsanguination, the liver was immediately excised, freeze-clamped between aluminum tongs (precooled with liquid nitrogen) and stored at $-80{ }^{\circ} \mathrm{C}$ for biochemical assays. Schematics of the study design are shown in Figure 1.

\section{STUDY DESIGN}

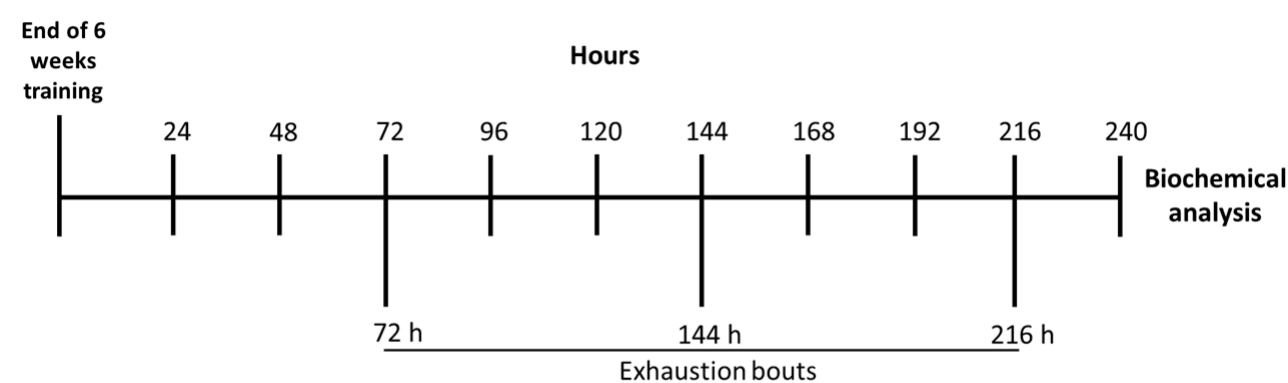

Diclofenac administration: $10 \mathrm{mg} / \mathrm{kg} /$ day

Figure 1. Timeline of the exercise training schedule, exhaustive protocol test, and data collection.

\subsection{Biochemical Plasma Parameters}

Plasma levels of glucose, creatinine kinase (CK), aspartate transaminase (AST), alanine transaminase (ALT), triglycerides (TG), total cholesterol (TC), uric acid (UA), high-density lipoprotein (HDL), albumin, and alkaline phosphatase (ALP) were estimated using commercially available standard biological kits (Labtest, Lagoa Santa, Brazil).

\subsection{Quantification of Extracellular Double-Stranded DNA (dsDNA)}

To assess cell damage/death, the presence of dsDNA fragments in the plasma was measured using PicoGreen ${ }^{\circledR}$ fluorescent assay [20]. The test was performed in 96-well fluo- 
rescence microplates using Quant-iT ${ }^{\mathrm{TM}}$ PicoGreen ${ }^{\circledR}$ kit (Invitrogen, Eugene, OR, USA), as per the manufacturer's instructions. The fluorescence measurements were recorded using a RF-5301 Shimadzu spectrofluorometer, wherein fluorescence emissions for PicoGreen ${ }^{\circledR}$ alone (blank) and PicoGreen ${ }^{\circledR}$ with DNA were recorded at room temperature $\left(25^{\circ} \mathrm{C}\right)$, with excitation and emission maxima of $480 \mathrm{~nm}$ and $520 \mathrm{~nm}$, respectively. Results were expressed in terms of fluorescence of dsDNA.

\subsection{IL-6 Levels}

The levels of IL- 6 in the liver and plasma were measured by enzyme linked immunosorbent assay, using a commercial kit (IL-6, eBIOSCIENCE ${ }^{\circledR}$, San Diego, CA, USA). Briefly, 96-well microplates were sensitized with the primary antibody at room temperature for $30 \mathrm{~min}$. Following this, the samples were added and incubated at $37^{\circ} \mathrm{C}$ for $30 \mathrm{~min}$. Further, the samples were washed as per the manufacturer's instructions. Post washing, a peroxidase-conjugated secondary antibody was added to each well. The concentration of the cytokines was determined in terms of the conversion of substrate, which was measured spectrophotometrically using a microplate reader at a wavelength of $480 \mathrm{~nm}$.

\subsection{Catalase (CAT) Activity}

The enzymatic activity of CAT was determined according to the method proposed by Aebi (1984) [21]. The CAT enzyme activity was measured in terms of the degradation of $\mathrm{H}_{2} \mathrm{O}_{2}$, where the absorbance of the colored reaction cocktail was measured at $240 \mathrm{~nm}$. The resulting data were corrected by protein content and expressed as the percentage of control.

\subsection{Glutathione Peroxidase (GPx) Activity}

The GPx activity was determined in terms of conversion of NADPH to NADP, which was measured spectrophotometrically at $340 \mathrm{~nm}$ [22]. The enzymatic reaction was initiated by the addition of $\mathrm{H}_{2} \mathrm{O}_{2}$ to a final concentration of $0.4 \mathrm{mM}$. The reaction was performed at $30{ }^{\circ} \mathrm{C}$ for $2 \mathrm{~min}$, and GPx activity was determined using a molar extinction coefficient of $6220 \mathrm{M}^{-1} \mathrm{~cm}^{-1}$. The GPx activity of the samples was expressed as a percentage of control.

\subsection{Glutathione Reductase (GR) Activity}

To determine GR activity, the enzymatic reaction was initiated by the addition of $20 \mathrm{mM}$ glutathione (oxidized). The reaction mixture was incubated at $30^{\circ} \mathrm{C}$ for $2 \mathrm{~min}$ and the measurements were performed at $340 \mathrm{~nm}$ [23]. The GR activity was determined using the molar extinction coefficient of $6220 \mathrm{M}^{-1} \mathrm{~cm}^{-1}$. The resulting sample readings were corrected by the protein content and expressed as a percentage of control.

\subsection{Reduced (GSH) and Oxidized (GSSG) Glutathione}

The levels of GSH and GSSG in the liver were measured as per the previously established method [24]. Fluorescent signals were recorded using a spectrofluorometer, with excitation and emission maxima of $350 \mathrm{~nm}$ and $420 \mathrm{~nm}$, respectively, and compared with linear standard curves for GSH and GSSG. The results were expressed as GSH/GSSG ratio.

\subsection{Citrate Synthase (CS) Activity}

Activity of CS in mixed gastrocnemius muscle and liver tissues was determined spectrophotometrically, according to the previously established method [25]. The tissue samples were homogenized and CS activity was measured in terms of the condensation of acetyl-CoA and oxaloacetate. The reaction was performed at $25^{\circ} \mathrm{C}$ and the concentration of resulting complex was determined at $412 \mathrm{~nm}$. The CS activity was expressed as percentage of control. 


\subsection{Protein Determination}

The protein content was determined using bovine serum albumin (BSA) $(1 \mathrm{mg} / \mathrm{mL})$ as standard, according to previously described protocol [26].

\subsection{Statistical Analyses}

All the datasets were subjected to statistical analyses using GraphPad Prism v.8.01 (Graphpad Inc., La Jolla, CA, USA). For continuous data showing normal distribution, datasets were analyzed using two-way analysis of variance, with 2 (diclofenac and saline treatments) $\times 2$ (sedentary and trained) variables. This was followed by Sidak's post hoc test, and $p$-values $<0.05$ were considered to be statistically significant. For each experimental set up, all data sets were expressed as means \pm SEM.

\subsection{In Silico Analysis}

The system biology approach combined with in silico analysis offers an efficient computational tool that can better explain interaction of bioactive molecules, such as diclofenac, with the signal molecules of various cellular pathways. In order to obtain curated genes/proteins, MitoCarta3.0 inventory was used, with a cut-off $\geq 2$ [27]. Subsequently, a chemical-protein (CP)-protein-protein interaction (PPI) (CP-PPI) network was proposed for Rattus norvergicus, based on the genes and inflammatory cytokines obtained from MitoCarta3.0 inventory, using a plug-in STITCH (stringApp 1.6) from Cytoscape 3.8.2 [28]. STITCH pipeline includes high-throughput experiments data, manually curated datasets, and results from multiple prediction methods into a single global network of protein-protein and protein-chemical interactions. In particular, STITCH tool allowed the visualization of the connections (edge) among different nodes (genes or proteins) and diclofenac-nodes, where each edge possessed a degree of confidence between 0 and 1.0. Here 0 represented lowest confidence and 1.0 represented highest confidence. For further analysis, nodes without any connections were excluded.

Further, MCODE 2.0.0 was used to predict clusters from CP-PPI network in which the existing nodes were modulated by diclofenac [29]. In particular, this plug-in predicts the occurrence of densely connected regions in a network on the basis of a graph-theoretic clustering algorithm. Following this, enrichment network analysis was performed using Cytoscape ClueGO 2.5.7 plug-in [30]. Gene ontology (GO) and Kyoto Encyclopedia of Genes and Genomes (KEGG) pathways are used to elucidate and describe molecular functions and biological and signal processes of genes. Updated annotations from $\mathrm{GO}$ and KEGG pathways were calculated using the hypergeometric test and a significant $p$-value threshold of 0.001 (FDR adjusted) was used for analysis.

For further analysis of the CP-PPI network, Cytoscape plug-in, CentiScaPe 3.2.1, was used, and degree and betweenness parameters were considered [30]. In general, degree indicates the number of adjacent nodes connected to a unique node, while betweenness refers to the number of shortest paths between two nodes that pass through a targeted node [31]. We finally investigated if there were hub-bottleneck (H-B) nodes possessing a high value of degree and betweenness which could be topologically crucial to the network structure.

\section{Results}

\subsection{Time to Exhaustion}

The present study evaluated the effects of administration of diclofenac $(10 \mathrm{mg} / \mathrm{kg} /$ day $)$ on the response to acute bouts of exercise in rats subjected to six weeks of swimming training. The time to exhaustion was calculated as a mean of the three exhaustion bouts tests, following six weeks of training program. As shown in Figure 2, animals from the Exe-Sal group exhibited an increased time to exhaustion as compared to the Sed-Sal group. However, no significant differences were reported between the Exe-Diclo and sedentary control groups. In fact, Exe-Diclo group was characterized by a lower time to exhaustion as compared to the Exe-Sal group, negating the effect of training on this parameter. 


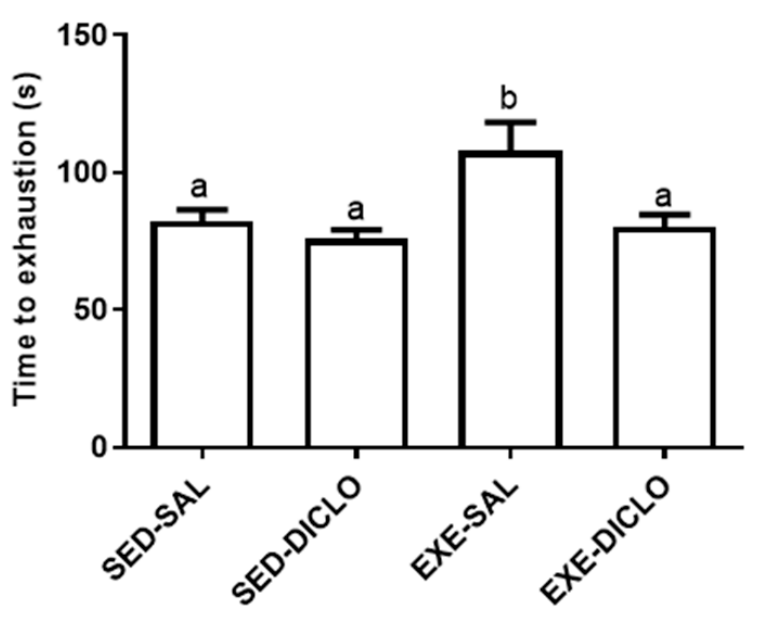

Figure 2. Effect of training and diclofenac treatment on time to exhaustion. At the end of six weeks of training period, trained and sedentary groups were divided into two groups each: sedentary-saline (Sed-Sal), sedentary-diclofenac (Sed-Diclo), exercise-saline (Exe-Sal), and exercise-diclofenac (ExeDiclo) groups. Following this, rats were subjected to three exhaustive swimming bouts, separated by a period of $72 \mathrm{~h}$. For each group, results represent the mean of the three bouts. Values are expressed as mean \pm SEM. Means for a variable with superscripts without a common letter differed significantly $(p<0.05)$.

\subsection{Physical Training Markers}

The present study evaluated the effect of training and diclofenac treatment on the activities of plasma CK and muscle CS enzymes. In general, CK and CS act as markers of muscle damage and metabolic activity, respectively. As shown in Figure 3, lower CK activity was recorded in plasma samples obtained from trained groups (Exe-Sal and ExeDiclo) as compared to the Sed-Sal group (Figure 3A). In comparison to this, the evaluation of muscle CS activity showed that Exe-Sal group was characterized by a higher CS activity as compared to the control group. No significant differences were recorded between CS activity of the Exe-Diclo and control groups; however, the CS activity of Exe-Diclo group was significantly lower as compared to the Exe-Sal group (Figure 3B).
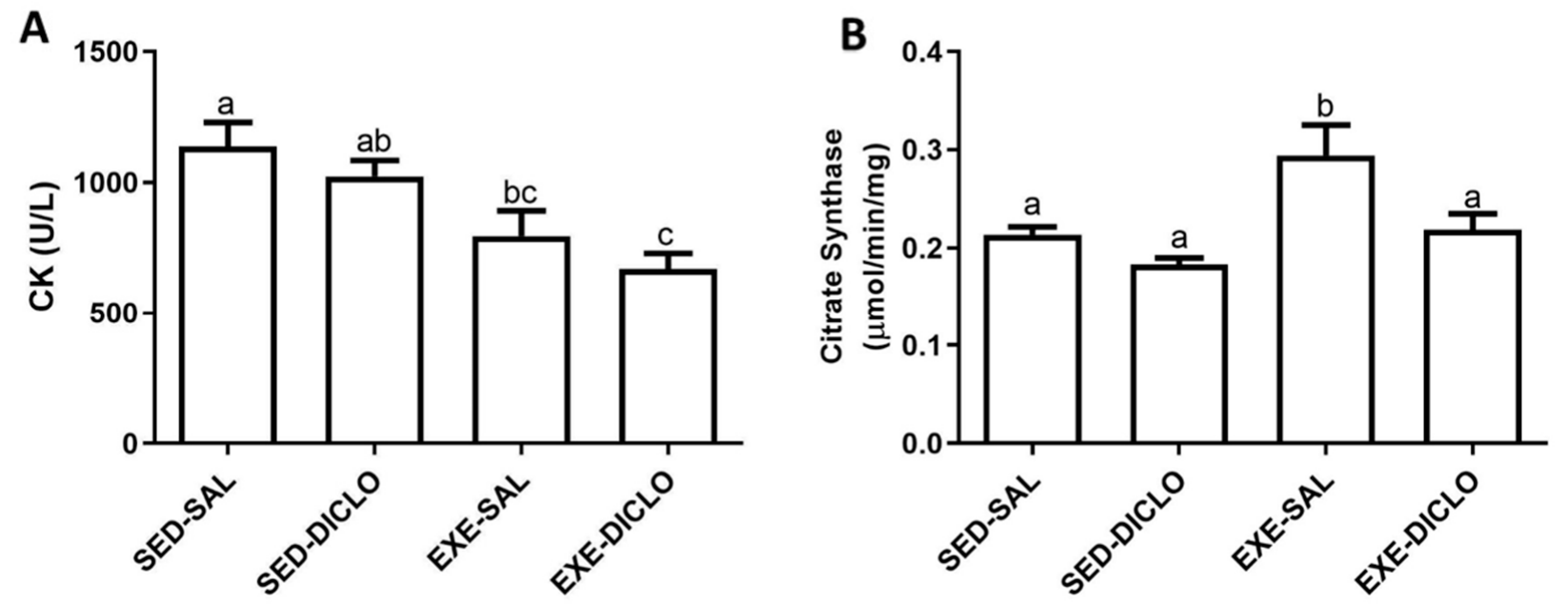

Figure 3. Effect of training and diclofenac treatment on the enzymatic activities of (A) plasma creatine kinase (CK) and (B) muscle citrate synthase (CS). Values are expressed as mean \pm SEM. Means for a variable with superscripts without a common letter differed significantly $(p<0.05)$. 


\subsection{Plasma Biochemical Parameters}

Both trained groups, Exe-Sal and Exe-Diclo, showed significantly lower triglycerides levels as compared to the control group, Sed-Sal (Table 1). Interestingly, no significant effect of exercise or diclofenac treatment was reported on glucose concentration, enzyme activities, or dsDNA content in the plasma samples.

Table 1. Effect of training and diclofenac treatment on plasma biochemical parameters.

\begin{tabular}{ccccc}
\hline & SED-SAL & SED-DICLO & EXE-SAL & EXE-DICLO \\
\hline Glucose (mmol/L) & $5.81 \pm 0.29$ & $5.02 \pm 0.19$ & $5.06 \pm 0.56$ & $4.98 \pm 0.33$ \\
Triglycerides (U/L) & $2.47 \pm 0.24 \mathrm{a}$ & $1.81 \pm 0.11 \mathrm{a}$ & $1.20 \pm 0.15 \mathrm{~b}$ & $1.54 \pm 0.24 \mathrm{~b}$ \\
ALT (mmol/L) & $58.5 \pm 3.54$ & $60.11 \pm 2.03$ & $58.38 \pm 1.85$ & $56.18 \pm 1.35$ \\
AST (mmol/L) & $90.02 \pm 3.20$ & $91.02 \pm 2.42$ & $87.11 \pm 1.22$ & $89.49 \pm 2.94$ \\
ALP (U/L) & $231.1 \pm 17.3$ & $203.8 \pm 17.3$ & $207.1 \pm 21.5$ & $217.4 \pm 15.7$ \\
dsDNA (fluorescence) & $23.74 \pm 5.53$ & $19.5 \pm 1.14$ & $19.61 \pm 2.29$ & $20.73 \pm 3.66$ \\
\hline
\end{tabular}

Values are expressed as mean \pm SEM. Means for a variable with superscripts without a common letter differed significantly $(p<0.05)$. ALT, alanine transaminase; AST, aspartate transaminase; ALP, alkaline phosphatase; dsDNA, double-stranded DNA.

\subsection{IL-6 Levels}

The effects of training and diclofenac administration on IL-6 levels in the plasma and liver are shown in Figure 4. As shown in Figure 4A, diclofenac administration resulted in a decrease in the plasma IL-6 levels. Interestingly, higher levels of IL-6 were recorded in the liver of Exe-Sal as compared to the control group; however, diclofenac treatment (Exe-Diclo group) resulted in a significant reduction in these effects (Figure 4B).

A

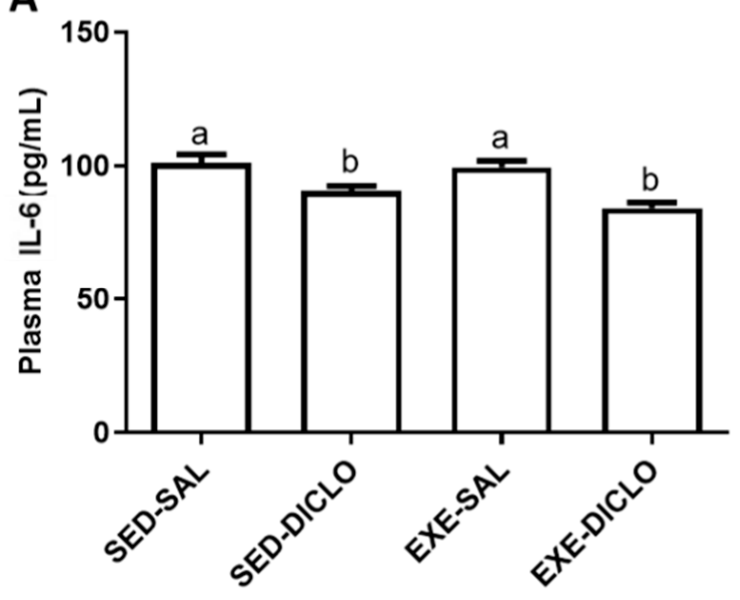

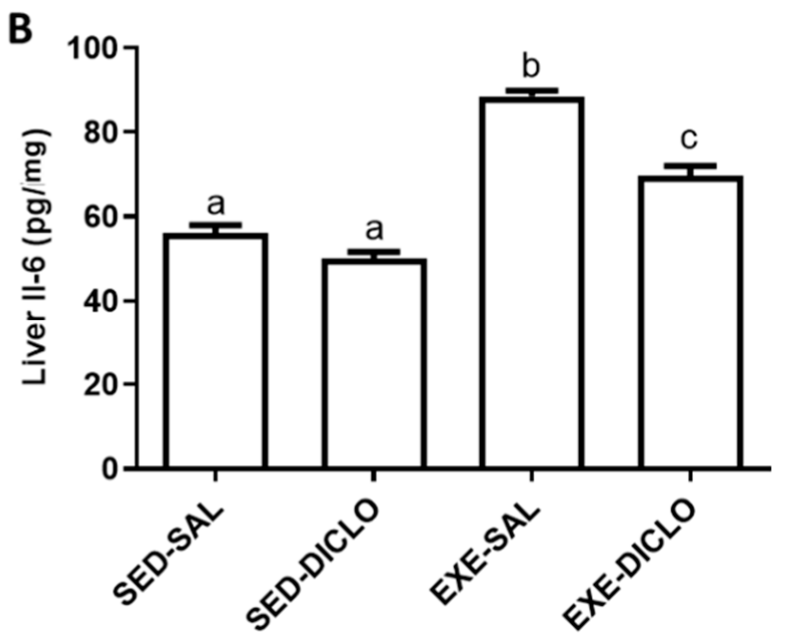

Figure 4. Effect of training and diclofenac treatment on the levels of interleukin-6 (IL-6) in (A) plasma and (B) liver. Values are expressed as mean \pm SEM. Means for a variable with superscripts without a common letter differed significantly $(p<0.05)$.

\subsection{In Silico Analysis and Redox Balance}

To generate the network, 1329 curated genes and proteins were used as initial input in the STITCH plug-in. As shown in Figure 5A, a CP-PPI network, comprising of 1236 nodes and 28,126 edges was generated. Following this, two topological analyses were applied, clustering and GO/KEGG enrichments. The use of MCODE identified the occurrence of only an enriched cluster in the CP-PPI network that was composed of 44 nodes, where a node was found to be directly modulated by diclofenac. This unique node modulated by diclofenac was identified to be the CAT enzyme. 
A CP-PPI network

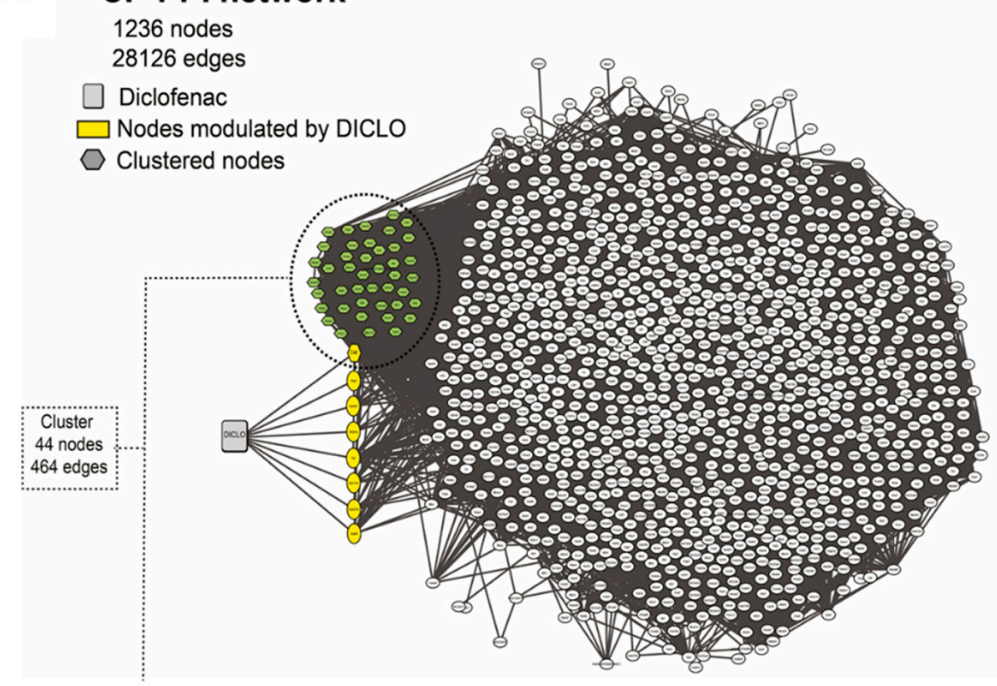

B
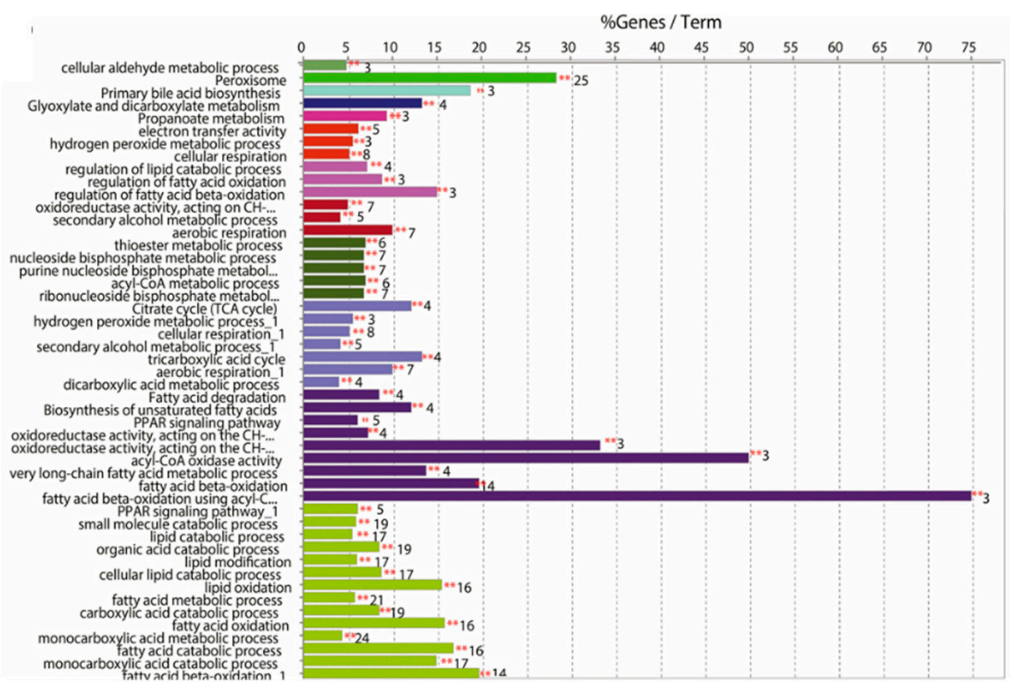

C

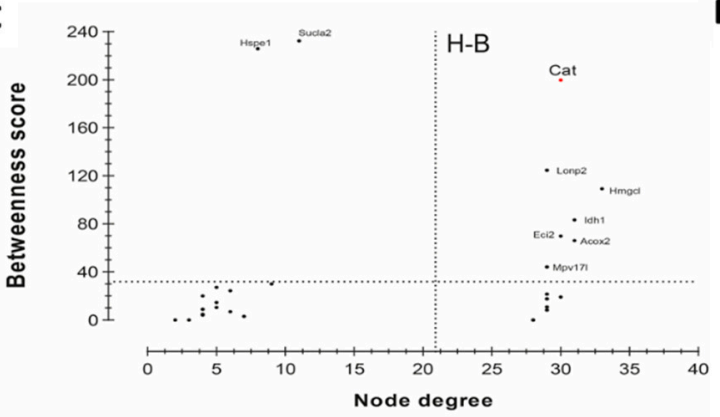

D

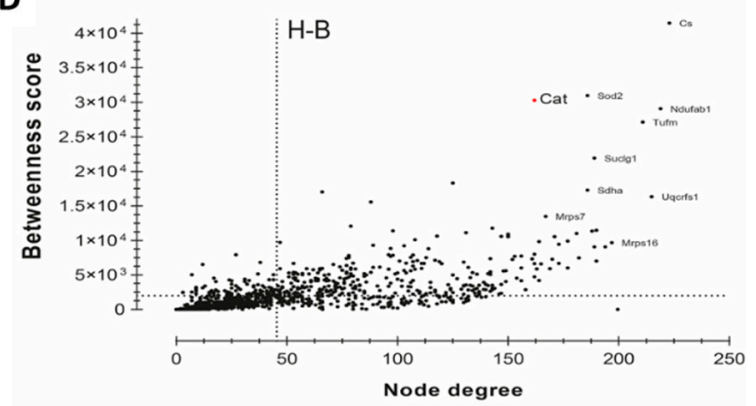

Figure 5. Systems biology analysis for the prediction of diclofenac interactors. (A) CP-PPI network. Significant module from this network was obtained using MCODE 2.0.0. Here, clustered genes/proteins are represented by nodes of different colors and diclofenac is represented by a square shape node. (B) GO/KEGG analyses were performed using ClueGO algorithms. Centrality analysis of (C) cluster and (D) CP-PPI network. Here, dashed lines represent the threshold value calculated for each centrality. Genes/proteins are represented by black dots, and catalase is denoted by a red dot. Only node scores above the network average are indicated; Hub-bottleneck (H-B).

To get better insights into the biological putative function or pathways involved within this cluster, enrichment analysis was performed using ClueGO software. Enrichment analysis is a method to identify classes of genes or proteins over-represented in a large set of 
genes or proteins and may associate with a specific cellular function into an annotation. As shown in Figure 5B, 49 GO terms were found to be significantly enriched, of which four groups possessed CAT. According to enrichment analysis, the main GO categories that were identified included peroxisome (corrected $p$-value $=4.28 \times 10^{-47}$ ), glyoxylate and dicarboxylate metabolism (corrected $p$-value $=3.82 \times 10^{-6}$ ), secondary alcohol metabolic process $\left(\right.$ corrected $p$-value $\left.=2.01 \times 10^{-12}\right)$, cellular respiration $\left(\right.$ corrected $p$-value $\left.=8.33 \times 10^{-11}\right)$, and hydrogen peroxide metabolic process (corrected $p$-value $=9.05 \times 10^{-9}$ ).

To investigate if CAT acted as a H-B node in the cluster or within the whole CP-PPI network, topological centrality analysis was performed. As shown in Figure 5C,D, CAT was identified as an H-B in the cluster and within all CP-PPI networks. These results suggested that CAT is a key node and pharmacological modulations on it can promote pathway-network perturbations.

Further, to validate the impact of diclofenac on CAT, the activity of CAT enzyme was measured in the experimental model used in the present study (Figure 6A). Liver CAT enzyme activity was found to be significantly higher in the Exe-Sal group as compared to its control, whereas the Exe-Diclo group showed lower CAT activity as compared to both Sed-Sal and Exe-Sal groups (Figure 6A).

A

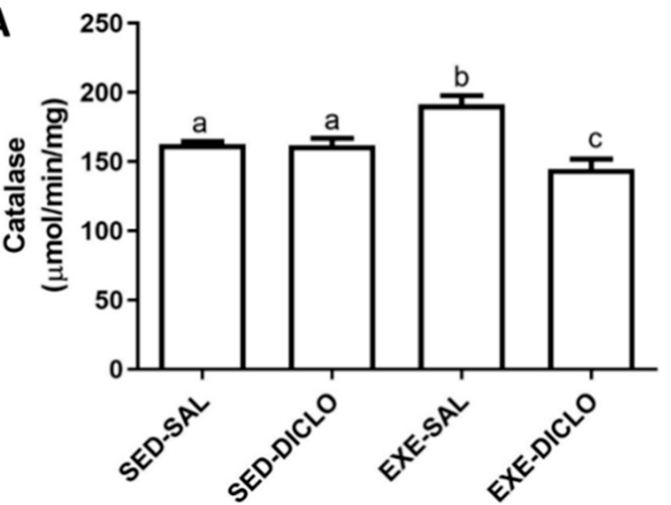

C

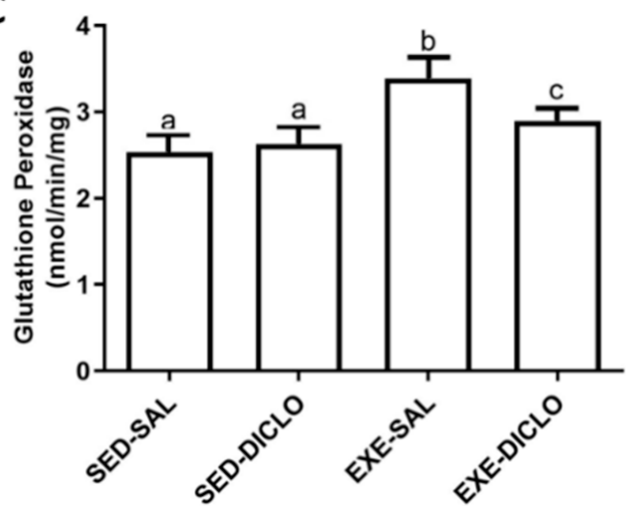

B

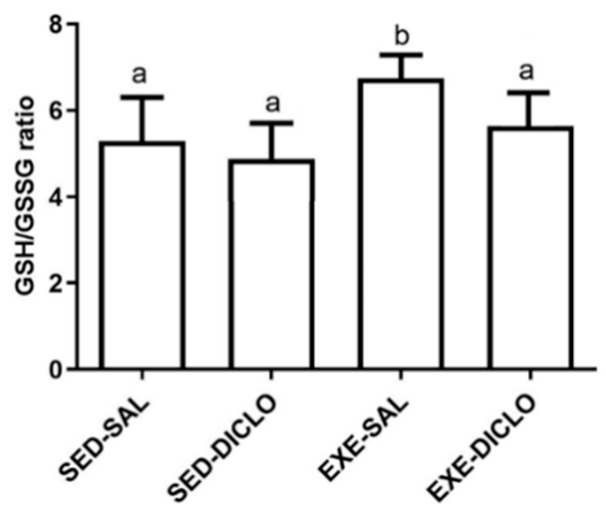

D

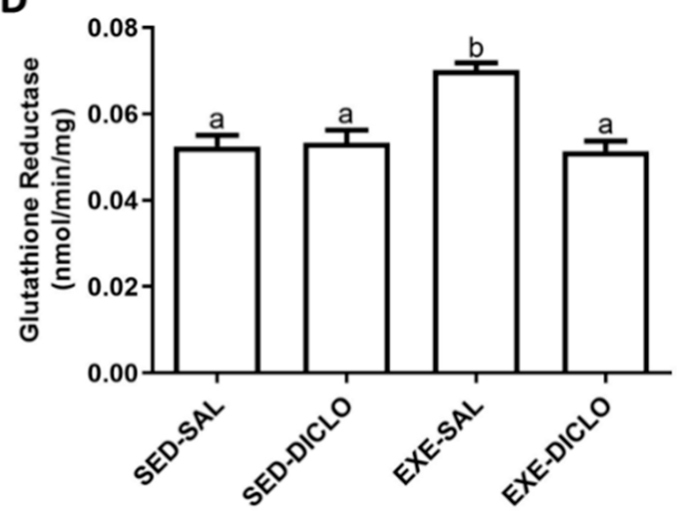

Figure 6. Effect of training and diclofenac treatment on redox parameters, (A) catalase (CAT) activity, (B) reduced to oxidized glutathione ratio (GSH/GSSG), (C) glutathione peroxidase (GPx) activity, and (D) glutathione reductase (GR) activity. Values are expressed as mean \pm SEM. Means for a variable with superscripts without a common letter differed significantly $(p<0.05)$.

In addition to this, diclofenac treatment introduced significant alternations in the levels of other components of the redox cycle as well. As shown in Figure 6B, an increased ratio of GSH/GSSG was reported in the Exe-Sal group as compared to the control, and this effect was blunted by diclofenac treatment (Exe-Diclo). Interestingly, augmented liver GPx activity was observed in the Exe-Sal group as compared to the control, and diclofenac treatment induced reduction in these values (Figure 6C). In particular, these values were significantly different from the Sed-Sal and Exe-Sal groups (Figure 6C). Similar results 
were reported for glutathione reductase (GR) activity (Figure 6D), where an increased GR activity was observed in the Exe-Sal group as compared to control, which was reversed by diclofenac treatment.

\section{Discussion}

The present study explored the impact of oral administration of diclofenac (10 $\mathrm{mg} / \mathrm{kg}$ body weight) on the response to acute bouts of exercise in rats, after six weeks of training period. In particular, the rats subjected to the 6-week swimming training program displayed reduced plasma CK levels and augmented muscle CS activity, after an exhaustion test. These results were in accordance with the findings of previous studies that reported favorable adaptations involving the aerobic metabolism in response to regular training [32,33]. Additionally, these results might also explain the observations regarding the increased time to reach exhaustion [34,35]. However, a 10-day diclofenac treatment, after training, blunted most of these changes, and a decreased time-to-exhaustion performance and reduced muscle CS enzyme activity was reported in groups receiving diclofenac. In concordance with previous findings, physical exercise decreased the plasma content of triglycerides. Interestingly, this effect was blocked by diclofenac treatment. More importantly, diclofenac treatment did not induce any significant changes in enzymatic activities or dsDNA content in plasma, indicating absence of any toxic effects of the drug.

Our results, particularly the inflammatory and redox status in the plasma and liver, highlighted that the training program activated specific tissue adaptive responses in rats. However, administration of diclofenac blunted most of these tissue adaptations. This is particularly important as no previous studies reported such a loss in tissue adaptation after regular exercise by the administration of a commonly used drug. A similar blocking of adaptation effects during training was previously reported with regard to antioxidant supplementation. In particular, antioxidants act as ROS and RNS scavengers, and thus produce a deleterious impact on muscle response to stress, leading to lower tissue adaptation after high-intensity exercises. This adaptation might be attributed to the fact that ROS and RNS act as signaling molecules, which are involved in enhancing protection against physical stress [36,37]. Several previous studies also reported that some drugs or supplements, such as caffeine and other NSAIDs, might impede long-term adaptations to physical exercise by preventing oxidative stress and inflammatory damage $[38,39]$. Thus, the performance losses observed in the present study might be related to reduction in tissue adaptations after diclofenac treatment.

Apart from this, the previous studies from our laboratory demonstrated that diclofenac pretreatment decreased the expression and content of several cytokines and proteins related to inflammatory pathways, such as TNF- $\alpha$, toll-like receptor-4, and p65 NF- $\mathrm{kB}$ subunit, after eccentric exercise bouts in rat muscle [8] and liver $[9,17]$. During sports competitions, or similar tasks, athletes need constant and increased muscle efforts, thereby making use of NSAID strategy quite common and useful. It ensures a fast recovery to the athlete that further allows them to participate in another competitive task, taking place within short durations of time. However, use of such strategies should be avoided for long-term adaptation as it may lead to a non-adapted tissue, blunting the beneficial effects of physical training, as reported in the present study.

In the present research, the trained group exhibited an increased level of IL-6, both in the plasma and liver. Post exercise training, such an increase in IL-6 production, is indeed a part of the adaptive mechanism, which provides a challenging environment to tissues and triggers them to respond to this inflammation process $[8,38]$. IL-6 is known to activate the immune system and improve glucose tolerance and insulin sensitivity after physical exercise [39,40]. Additionally, IL-6 has been previously shown to stimulate the release of IL-1Ra and IL-10 in human mononuclear cells [41], and to inhibit the transcription of IL-1 and TNF- $\alpha$ [42]. Similar results for IL-6 were reported in the present case. In particular, these mechanisms are triggered by several factors, including training frequency, intensity, volume, and the experimental model [43]. Here, diclofenac treatment blunted this response, 
and lower levels of IL-6 were reported in the plasma and liver of Exe-Diclo animals as compared to the trained but non-treated animals (Exe-Sal group). The anti-inflammatory effects of diclofenac are widely reported, and these effects might be responsible for the observed reduction in the tissue response mechanisms, which further resulted in a less adapted organism.

Several authors reported a well-established relationship between physical exercise, inflammation, and oxidative stress $[44,45]$. Thus, a systems biology approach was utilized to define putative targets of diclofenac, related to inflammation and oxidative stress. The results for topological analysis identified a cluster of 44 nodes, where only CAT enzyme was found to be directly modulated by diclofenac. In particular, this modulation regulated several other cellular processes (GO analysis), including glyoxylate and dicarboxylate metabolism, hydrogen peroxide metabolism, and cellular respiration. Importantly, CAT was identified as an H-B node in this cluster as well as in the entire CP-PPI network. Further analysis showed that CAT, by itself, was a highly connected node, which controlled the flow of information within the network. According to the theory of graphs, pharmacological modulation on H-B might induce pathway-network perturbations [46]. In the present case, these were reflected by a reduction in CAT activity in the trained animals receiving diclofenac. It has been previously demonstrated that diclofenac treatment suppressed CAT activity in gills but increased GPx activity, probably as a compensatory mechanism to reduce the accumulation of $\mathrm{H} 2 \mathrm{O} 2$ [47]. The present study also assessed the effect of diclofenac on the glutathione redox cycle in rat model. Similar to the results reported in gills, the trained group displayed higher values for the ratio of GSH/GSSG, GR, and GPx enzyme activities. These results corresponded to the upregulation of antioxidant defense system, a signaling pathway that counteracted the inflammatory pathways triggered by acute bouts of exhausting exercise $[8,45,48]$ and related to the increase in IL-6 $[40,49]$.

\section{Conclusions}

The present study confirmed that chronic exercise training program triggers tissue adaptation mechanisms, which further contribute to better performances in tasks as observed in time-to-exhaustion tests. It also induces minor tissue damages after acute exercise. In particular, these adaptation mechanisms involved an increase in the liver and plasma inflammatory responses, such as cytokine production and release, and induction of oxidative stress. Further, the study highlighted that diclofenac treatment, which was aimed to reduce pain and provide a fast recovery after acute physical exercise, might result in a loss in exercise performance and tissue adaptations in the long term, mediated by blockage of the inflammatory/oxidative stress processes. Future studies are required to validate and identify the mechanisms responsible for the relevant role of CAT enzyme, which was identified using systems biology analysis.

Author Contributions: Conceptualization, R.P.B., L.F.F.R. and J.G.-G.; methodology, R.P.B., A.A.C., I.K.d.S., F.D.L. and J.E.V.; formal analysis, all authors; investigation, all authors; writing-original draft, R.P.B., C.T. and J.E.V.; writing-review and editing, all authors; visualization, all authors; supervision, F.A.A.S. and J.G.-G. All authors have read and agreed to the published version of the manuscript.

Funding: This research received no external funding.

Institutional Review Board Statement: The study was conducted and approved by the Institutional Review Board (or Ethics Committee) of Ethics Committee for Animal Research of the Universidade Federal de Santa Maria (UFSM, permit number 115/2010).

Informed Consent Statement: Not applicable.

Data Availability Statement: Data is contained within the article.

Acknowledgments: The work was supported by the PRONEM/CNPq/FAPERGS 16/25510000248-7 and CAPES/PROEX 23038.005848/2018-31 research grants. FAAS received a fellowship from CNPQ. CIBERehd is funded by Instituto de Salud Carlos III, Spain. 
Conflicts of Interest: The authors declare no conflict of interest.

\section{References}

1. Warburton, D.E.R.; Nicol, C.W.; Bredin, S.S.D. Health benefits of physical activity: The evidence. CMAJ 2006, 174, 801-809. [CrossRef] [PubMed]

2. Ruegsegger, G.N.; Booth, F.W. Health benefits of exercise. Cold Spring Harb. Perspect. Med. 2018, 8, a029694. [CrossRef] [PubMed]

3. Mikkelsen, U.R.; Schjerling, P.; Helmark, I.C.; Reitelseder, S.; Holm, L.; Skovgaard, D.; Langberg, H.; Kjaer, M.; Heinemeier, K.M. Local NSAID infusion does not affect protein synthesis and gene expression in human muscle after eccentric exercise. Scand. J. Med. Sci. Sports 2011, 21, 630-644. [CrossRef] [PubMed]

4. Schreijenberg, M.; Luijsterburg, P.A.J.; Van Trier, Y.D.M.; Rizopoulos, D.; Koopmanschap, M.A.; Voogt, L.; Maher, C.G.; Koes, B.W Efficacy of paracetamol, diclofenac and advice for acute low back pain in general practice: Design of a randomized controlled trial (PACE Plus). BMC Musculoskelet. Disord. 2017, 18, 56. [CrossRef]

5. Vaso, M.; Weber, A.; Tscholl, P.M.; Junge, A.; Dvorak, J. Use and abuse of medication during 2014 FIFA World Cup Brazil: A retrospective survey. BMJ Open 2015, 5, e007608. [CrossRef] [PubMed]

6. Huang, S.H.; Johnson, K.; Pipe, A.L. The use of dietary supplements and medications by Canadian athletes at the Atlanta and Sydney Olympic Games. Clin. J. Sport Med. 2006, 16, 27-33. [CrossRef]

7. Ziltener, J.L.; Leal, S.; Fournier, P.E. Non-steroidal anti-inflammatory drugs for athletes: An update. Ann. Phys. Rehabil. Med. 2010, 53, 278-288. [CrossRef]

8. Barcelos, R.P.; Bresciani, G.; Cuevas, M.J.; Martínez-Flórez, S.; Soares, F.A.A.; González-Gallego, J. Diclofenac pretreatment modulates exercise-induced inflammation in skeletal muscle of rats through the TLR4/NF-kB pathway. Appl. Physiol. Nutr. Metab. 2017, 42, 757-764. [CrossRef]

9. Steckling, F.M.; Lima, F.D.; Farinha, J.B.; Rosa, P.C.; Royes, L.F.F.; Cuevas, M.J.; Bresciani, G.; Soares, F.A.; González-Gallego, J.; Barcelos, R.P. Diclofenac attenuates inflammation through TLR4 pathway and improves exercise performance after exhaustive swimming. Scand. J. Med. Sci. Sport. 2020, 30, 264-271. [CrossRef]

10. Moghetti, P.; Bacchi, E.; Brangani, C.; Donà, S.; Negri, C. Metabolic effects of Exercise. Front. Horm. Res. 2016, 47, 44-57. [CrossRef]

11. Murton, A.J.; Greenhaff, P.L. Resistance exercise and the mechanisms of muscle mass regulation in humans: Acute effects on muscle protein turnover and the gaps in our understanding of chronic resistance exercise training adaptation. Int. J. Biochem. Cell Biol. 2013, 45, 2209-2214. [CrossRef]

12. Vargas, J.E.; Puga, R.; Lenz, G.; Trindade, C.; Filippi-Chiela, E. Cellular Mechanisms triggered by the cotreatment of resveratrol and doxorubicin in breast cancer: A translational in vitro-in silico model. Oxidative Med. Cell. Longev. 2020, $2020,5432651$. [CrossRef] [PubMed]

13. Zhang, W.; Huai, Y.; Miao, Z.; Qian, A.; Wang, Y. Systems pharmacology for investigation of the mechanisms of action of traditional chinese medicine in drug discovery. Front. Pharmacol. 2019, 10, 743. [CrossRef] [PubMed]

14. Vargas, J.E.; Puga, R.; Poloni, J.D.F.; Saraiva Macedo Timmers, L.F.; Porto, B.N.; Norberto De Souza, O.; Bonatto, D.; Condessa Pitrez, P.M.; Tetelbom Stein, R. A network flow approach to predict protein targets and flavonoid backbones to treat respiratory syncytial virus infection. BioMed Res. Int. 2015, 2015, 301635. [CrossRef]

15. Lima, F.D.; Stamm, D.N.; Della Pace, I.D.; Ribeiro, L.R.; Rambo, L.M.; Bresciani, G.; Ferreira, J.; Rossato, M.F.; Silva, M.A.; Pereira M.E.; et al. Ibuprofen intake increases exercise time to exhaustion: A possible role for preventing exercise-induced fatigue. Scand. J. Med. Sci. Sports 2015, 26, 1160-1170. [CrossRef]

16. De Araujo, G.G.; Papoti, M.; Manchado, F.e.B.; de Mello, M.A.; Gobatto, C.A. Protocols for hyperlactatemia induction in the lactate minimum test adapted to swimming rats. Comp. Biochem. Physiol. A Mol. Integr. Physiol. 2007, 148, 888-892. [CrossRef] [PubMed]

17. Barcelos, R.P.; Bresciani, G.; Rodriguez-Miguelez, P.; Cuevas, M.J.; Soares, F.A.A.; Barbosa, N.V.; González-Gallego, J. Diclofenac pretreatment effects on the toll-like receptor 4/nuclear factor kappa B-mediated inflammatory response to eccentric exercise in rat liver. Life Sci. 2016, 148, 247-253. [CrossRef] [PubMed]

18. Deng, X.; Stachlewitz, R.F.; Liguori, M.J.; Blomme, E.A.; Waring, J.F.; Luyendyk, J.P.; Maddox, J.F.; Ganey, P.E.; Roth, R.A. Modest inflammation enhances diclofenac hepatotoxicity in rats: Role of neutrophils and bacterial translocation. J. Pharmacol. Exp. Ther. 2006, 319, 1191-1199. [CrossRef]

19. Al-dossari Manal, H.; Fadda, L.M.; Attia, H.A.; Hasan, I.H.; Mahmoud, A.M. Curcumin and selenium prevent lipopolysaccharide/diclofenac-induced liver injury by suppressing inflammation and oxidative stress. Biol. Trace Elem. Res. 2020, 196, 173-183. [CrossRef]

20. Georgiou, C.D.; Papapostolou, I.; Grintzalis, K. Protocol for the quantitative assessment of DNA concentration and damage (fragmentation and nicks). Nat. Protoc. 2009, 4, 125-131. [CrossRef]

21. Aebi, H. Catalase in vitro. Methods Enzym. 1984, 105, 121-126. [CrossRef]

22. Flohé, L.; Günzler, W.A. Assays of glutathione peroxidase. Methods Enzym. 1984, 105, 114-121. [CrossRef]

23. Carlberg, I.; Mannervik, B. Glutathione reductase. Methods Enzym. 1985, 113, 484-490. [CrossRef]

24. Hissin, P.J.; Hilf, R. A fluorometric method for determination of oxidized and reduced glutathione in tissues. Anal. Biochem. 1976, 74, 214-226. [CrossRef]

25. Srere, P.A. Studies on purified citrate-enzymes: Metabolic interpretations. Biochem. Soc. Symp. 1968, 27, 11-21. [PubMed] 
26. Bradford, M.M. A rapid and sensitive method for the quantitation of microgram quantities of protein utilizing the principle of protein-dye binding. Anal. Biochem. 1976, 72, 248-254. [CrossRef]

27. Rath, S.; Sharma, R.; Gupta, R.; Ast, T.; Chan, C.; Durham, T.J.; Goodman, R.P.; Grabarek, Z.; Haas, M.E.; Hung, W.H.W.; et al. MitoCarta3.0: An updated mitochondrial proteome now with sub-organelle localization and pathway annotations. Nucleic Acids Res. 2021, 49, D1541-D1547. [CrossRef]

28. Doncheva, N.T.; Morris, J.H.; Gorodkin, J.; Jensen, L.J. Cytoscape StringApp: Network analysis and visualization of proteomics data. J. Proteome Res. 2019, 18, 623-632. [CrossRef] [PubMed]

29. Bader, G.D.; Hogue, C.W.V. An automated method for finding molecular complexes in large protein interaction networks. BMC Bioinform. 2003, 4, 2. [CrossRef]

30. Bindea, G.; Mlecnik, B.; Hackl, H.; Charoentong, P.; Tosolini, M.; Kirilovsky, A.; Fridman, W.H.; Pagès, F.; Trajanoski, Z.; Galon, J. ClueGO: A Cytoscape plug-in to decipher functionally grouped gene ontology and pathway annotation networks. Bioinformatics 2009, 25, 1091-1093. [CrossRef]

31. Scardoni, G.; Petterlini, M.; Laudanna, C. Analyzing biological network parameters with CentiScaPe. Bioinformatics 2009, 25, 2857-2859. [CrossRef]

32. Meinild Lundby, A.K.; Jacobs, R.A.; Gehrig, S.; de Leur, J.; Hauser, M.; Bonne, T.C.; Flück, D.; Dandanell, S.; Kirk, N.; Kaech, A.; et al. Exercise training increases skeletal muscle mitochondrial volume density by enlargement of existing mitochondria and not de novo biogenesis. Acta Physiol. 2018, 222, e12905. [CrossRef] [PubMed]

33. Parry, H.A.; Roberts, M.D.; Kavazis, A.N. Human skeletal muscle mitochondrial adaptations following resistance exercise training. Int. J. Sports Med. 2020, 41, 349-359. [CrossRef] [PubMed]

34. Ravi Kiran, T.; Subramanyam, M.V.; Asha Devi, S. Swim exercise training and adaptations in the antioxidant defense system of myocardium of old rats: Relationship to swim intensity and duration. Comp. Biochem. Physiol. B Biochem. Mol. Biol. 2004, 137, 187-196. [CrossRef]

35. Lima, F.D.; Stamm, D.N.; Della-Pace, I.D.; Dobrachinski, F.; de Carvalho, N.R.; Royes, L.F.; Soares, F.A.; Rocha, J.B.; GonzálezGallego, J.; Bresciani, G. Swimming training induces liver mitochondrial adaptations to oxidative stress in rats submitted to repeated exhaustive swimming bouts. PLoS ONE 2013, 8, e55668. [CrossRef]

36. Merry, T.L.; Ristow, M. Do antioxidant supplements interfere with skeletal muscle adaptation to exercise training? J. Physiol. 2016, 594, 5135-5147. [CrossRef]

37. Higgins, M.R.; Izadi, A.; Kaviani, M. Antioxidants and exercise performance: With a focus on vitamin e and c supplementation. Int. J. Environ. Res. Public Health 2020, 17, 8452. [CrossRef]

38. Deshmukh, A.S.; Steenberg, D.E.; Hostrup, M.; Birk, J.B.; Larsen, J.K.; Santos, A.; Kjøbsted, R.; Hingst, J.R.; Schéele, C.C.; Murgia, M.; et al. Deep muscle-proteomic analysis of freeze-dried human muscle biopsies reveals fiber type-specific adaptations to exercise training. Nat. Commun. 2021, 12, 304. [CrossRef]

39. Pal, M.; Febbraio, M.A.; Whitham, M. From cytokine to myokine: The emerging role of interleukin-6 in metabolic regulation. Immunol. Cell Biol. 2014, 92, 331-339. [CrossRef]

40. Gonzalez-Gil, A.M.; Elizondo-Montemayor, L. The role of exercise in the interplay between myokines, hepatokines, osteokines, adipokines, and modulation of inflammation for energy substrate redistribution and fat mass loss: A review. Nutrients 2020, 12, 1899. [CrossRef]

41. Steensberg, A.; Fischer, C.P.; Keller, C.; Møller, K.; Pedersen, B.K. IL-6 enhances plasma IL-1ra, IL-10, and cortisol in humans. Am. J. Physiol. Endocrinol. Metab. 2003, 285, E433-E437. [CrossRef] [PubMed]

42. Schindler, R.; Mancilla, J.; Endres, S.; Ghorbani, R.; Clark, S.; Dinarello, C. Correlations and interactions in the production of interleukin-6 (IL-6), IL-1, and tumor necrosis factor (TNF) in human blood mononuclear cells: IL-6 suppresses IL-1 and TNF. Blood 1990, 75, 40-47. [CrossRef] [PubMed]

43. Georgakouli, K.; Manthou, E.; Fatouros, I.G.; Deli, C.K.; Spandidos, D.A.; Tsatsakis, A.M.; Kouretas, D.; Koutedakis, Y.; Theodorakis, Y.; Jamurtas, A.Z. Effects of acute exercise on liver function and blood redox status in heavy drinkers. Exp. Ther. Med. 2015, 10, 2015-2022. [CrossRef] [PubMed]

44. Magherini, F.; Fiaschi, T.; Marzocchini, R.; Mannelli, M.; Gamberi, T.; Modesti, P.A.; Modesti, A. Oxidative stress in exercise training: The involvement of inflammation and peripheral signals. Free Radic. Res. 2019, 53, 1155-1165. [CrossRef]

45. Pillon Barcelos, R.; Freire Royes, L.F.; Gonzalez-Gallego, J.; Bresciani, G. Oxidative stress and inflammation: Liver responses and adaptations to acute and regular exercise. Free Radic. Res. 2017, 51, 222-236. [CrossRef]

46. Harrold, J.M.; Ramanathan, M.; Mager, D.E. Network-based approaches in drug discovery and early development. Clin. Pharmacol. Ther. 2013, 94, 651-658. [CrossRef]

47. Lubiana, P.; Prokkola, J.M.; Nikinmaa, M.; Burmester, T.; Kanerva, M.; Götting, M. The effects of the painkiller diclofenac and hypoxia on gene transcription and antioxidant system in the gills of three-spined stickleback. Comp. Biochem. Physiol. Part $\mathrm{C}$ Toxicol. Pharmacol. 2016, 185-186, 147-154. [CrossRef]

48. Francaux, M. Toll-like receptor signalling induced by endurance exercise. Appl. Physiol. Nutr. Metab. 2009, 34, 454-458. [CrossRef] [PubMed]

49. Fischer, C.P. Interleukin-6 in acute exercise and training: What is the biological relevance? Exerc. Immunol. Rev. 2006, 12, 6-33. 